\title{
Electrochemical Assay for Glycated Hemoglobin based on the Magnetic Particle-supported Concentration Coupled to Boronate-diol Interactions
}

\author{
Seo Young Son, Yong Duk Han, Kyeong-Hee Lee, ${ }^{\dagger}$ and Hyun C. Yoon* \\ Department of Molecular Science \& Technology, Ajou University, Suwon 443-749, Korea. *E-mail: hcyoon@ajou.ac.kr \\ ${ }^{\dagger}$ Advanced Medical Device Research Center, KERI, Ansan 426-170, Korea \\ Received March 29, 2010, Accepted May 31, 2010
}

Key Words: Electrochemical assay, Glycated hemoglobin, $\mathrm{Hb}_{1 \mathrm{C}}$, Magnetic particle, Modified microparticle

The separation of a specific target protein from a complex biochemical sample is important in many areas of analytical sciences. Researchers are investigating new and effective separation methods because the separation process significantly affects the price of production. The latest separation technology using a magnetic field has received much attention due to its diverse applications and because it simplifies the adsorption and separation steps. ${ }^{1}$ This method has several advantages, including speed, simplicity, and excellent selectivity. Both small $(50 \sim 200 \mathrm{~nm})$ and large ( $1 \mu \mathrm{m}$ and above) magnetic particles (MPs) can be used in biomolecular separation. A superparamagnetic particle has the unique and important property of exhibiting magnetism only when under a magnetic field. This means that the target molecule readily returns to a fluid medium after the magnetic separation, maintaining its initial biomolecular activity and enabling further treatments with ease. ${ }^{2}$ Applications that are currently being studied with MPs include separation, stabilization, detection, and molecular delivery. ${ }^{3}$ The linkage of MPs and biomolecules can be accomplished by introducing reactive groups, which biospecifically interact with the target molecules, onto the MP surface. Among several biospecific reactive groups, metal cation reacts and binds to the specific proteins. Binding of specific amino acid residues to free coordination site of metal cation affects to polypeptide folding and induces conformational change of proteins. ${ }^{4}$ These metal cationprotein binding properties have been used in protein purification, for example, in the immobilized metal cation affinity chromatography (IMAC). ${ }^{5}$ Especially, zinc cation exhibits affinity with hemoglobin and binds to specific histidine and cysteine residues of the hemoglobin structure. ${ }^{6}$ The zinc-hemoglobin interaction induces conformational changes of the hemoglobin that induces coagulation. ${ }^{7,8}$ Frantzen group demonstrated that zinc cations were able to selectively precipitate hemoglobin from whole blood lysate by controlling the hemoglobin/zinc cation ratio. ${ }^{8}$

As a subtype of hemoglobin, glycated hemoglobin $\left(\mathrm{HbA}_{1 \mathrm{C}}\right)$ is a widely used marker for long-term treatment and control of diabetes mellitus. ${ }^{9} \mathrm{HbA}_{1 \mathrm{C}}$ is formed when an amino terminal of the hemoglobin $\beta$ chain is glycated under conditions of uncontrolled high blood glucose concentration. ${ }^{10}$ Glucose binds nonenzymatically to hemoglobin slowly (about $0.05 \%$ per day) and indicates the average glucose level approximately 120 days prior to measurement, which corresponds to the lifetime of red blood cells.
Various methodologies have been applied for $\mathrm{HbA}_{1 \mathrm{C}}$ detection, including boronate affinity chromatography, immunoassay, ion-exchange chromatography, colorimetry, and mass spectroscopy. ${ }^{11}$ However, these approaches necessitate complex instrumentations and operation procedures. We have employed the electrochemical approach to evaluate the levels of $\mathrm{HbA}_{1 \mathrm{C}}$ to overcome these disadvantages. For the electrochemical detection, the carbohydrate moiety from the molecular surface of $\mathrm{HbA}_{1 \mathrm{C}}$ can be employed as the targeting site. ${ }^{12}$

The carbohydrate of $\mathrm{HbA}_{1 \mathrm{C}} \beta$ chain is reacted with boronate compounds containing electroactive groups, resulting in the formation of boronate-diol complexes. ${ }^{13,14}$ Additionally, to achieve an accurate detection of $\mathrm{HbA}_{1 \mathrm{C}}$, the hemoglobin separation steps are required. With unnecessary proteins such as albumins, antibodies and enzymes in hemolysates, these could act as signal interferences in the electrochemical detection of glycated hemoglobin. In this study, a zinc-modified superparamagnetic MP (ZnMP) was introduced to concentrate and purify $\mathrm{HbA}_{1 \mathrm{C}}$ efficiently. As a zinc chelating ligand, ethylene diamine tetraacetic acid (EDTA) was introduced to modify zinc cations to the surface of the MP. As shown by previous reports, EDTA could be covalently immobilized to amine-modified solid surface. ${ }^{15-17}$ Under the condition of the suitable conformation, EDTA can be immobilized onto the amine-modified solid surface maintaining its chelating capability to zinc cations in situ. ${ }^{16,17}$

With the aid of ZnMP, an electrochemical assay using ferrocene boronate (FcBA) as a signaling tag was developed for $\mathrm{HbA}_{1 \mathrm{C}}$. FcBA is pertinent to the signal registration according to the concentration of $\mathrm{HbA}_{1 \mathrm{C}}$, because the FcBA molecule contains both diol-reactive boronic acid and electroactive ferrocenyl groups. Also, by using permanent magnet, $\mathrm{ZnMP}-\mathrm{HbA}_{1 \mathrm{C}^{-}}$ FcBA conjugates could be magnetically deposited and concentrated to the surface of a working electrode, providing signaling of amplified electrochemical currents. Details are reported herein.

\section{Results and Discussion}

The key purpose of this study is to discover an effective method to purify the $\mathrm{HbA}_{1 \mathrm{C}}-\mathrm{FcBA}$ conjugate from unreacted FcBA for precise electroanalysis of $\mathrm{HbA}_{1 \mathrm{C}}$. Typically, centrifugation and filtration have been used to remove particles from fluid. However, these methods are time-consuming and complex, and require specific equipment such as filters and 
(A)

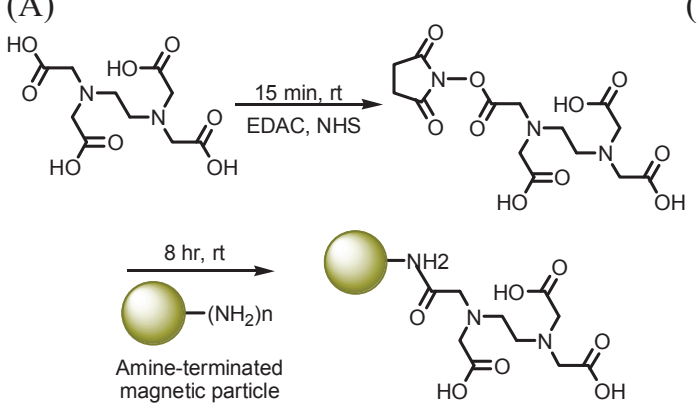

(B)

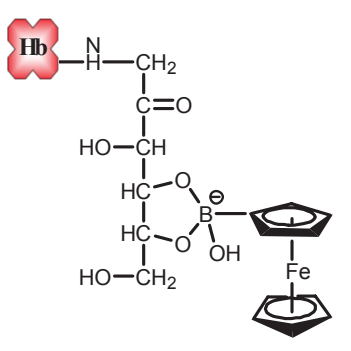

(C)

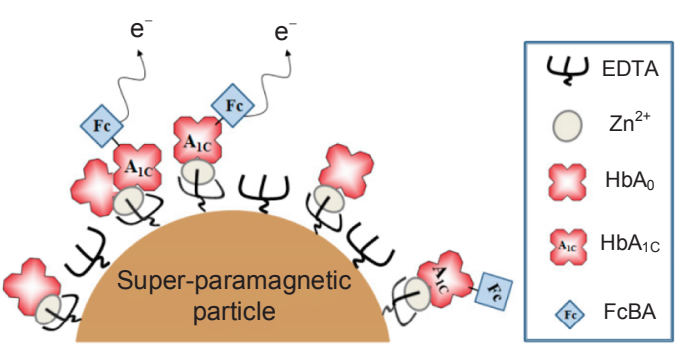

Scheme 1. Schematic illustrations of (A) the preparation steps of EDTA-terminated magnetic particles, (B) the chemical structure of conjugation adduct between $\mathrm{HbA}_{1 \mathrm{C}}$ and $\mathrm{FcBA}$, and (C) the MP-assisted concentration of target $\mathrm{HbA}_{1 \mathrm{C}}$ and electrochemical signaling with ZnMP/ $\mathrm{HbA}_{1 \mathrm{C}}-\mathrm{FcBA}$.

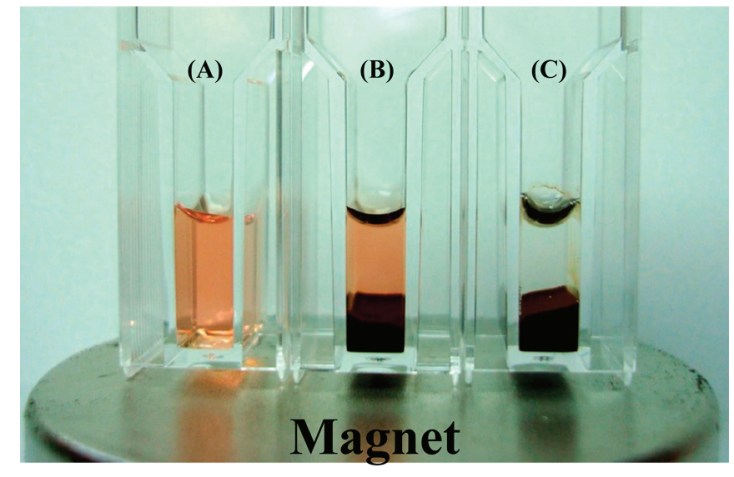

Figure 1. Comparison of three cuvettes on a permanent magnet. Samples are $1.0 \mathrm{mg} / \mathrm{mL} \mathrm{HbA}_{1 \mathrm{C}}$ mixed with (A) phosphate buffer solution only, (B) EDTA-terminated magnetic particles, and (C) ZnMPs, respectively.

ultrafiltration systems. Magnetic separation, purification using surface-modified MPs, overcomes the weaknesses of the conventional methods. In this study, MPs have the ability to specifically bind with $\mathrm{HbA}_{1 \mathrm{C}}$, once the MPs have been modified with zinc ion (ZnMP). Scheme 1 illustrates overall process of this work including the preparation of EDTA-terminated magnetic particles, the adduct from boronate-diol interaction between $\mathrm{HbA}_{1 \mathrm{C}}$ and $\mathrm{FcBA}$ and the purified product of $\mathrm{ZnMP} /$ $\mathrm{HbA}_{1 \mathrm{C}}-\mathrm{FcBA}$ after the conjugation and purification steps. Details are in the experimental section.

After ZnMP preparation, confirmatory experiments were conducted to determine the reaction between ZnMPs and hemoglobin, including glycated hemoglobin $\left(\mathrm{HbA}_{\mathrm{IC}}\right)$ and non-glycated normal hemoglobin $\left(\mathrm{HbA}_{0}\right)$. Figure 1 shows three cuvettes subjected to spectrophotometry on the magnet: the first cuvette on the left (A) contained $\mathrm{HbA}_{1 \mathrm{C}}$ only, and the color of the solution was red, showing even dispersal of hemoglobin molecules in solution. The middle cuvette (B) and the one on the right (C) contained hemoglobin mixed with EDTA-terminated MPs and ZnMP, respectively. Under the magnetic field, both EDTAterminated MPs and ZnMPs were deposited at the bottom of the cuvette. In the cuvette $(\mathrm{C})$, for the ZnMP treatment, the supernatant was very clear, showing that hemoglobin was collected successfully. However, in cuvette (B) for EDTA-termi- nated MPs, the supernatant mixture was still red in color, indicating that the hemoglobin had not successfully combined with these MPs. From these results, we could confirm that hemoglobin interacted with zinc ion on the surface of ZnMPs, while hemoglobins did not interact with the EDTA-terminated MP itself.

To confirm the reaction between ZnMPs and hemoglobin, the binding capacity of ZnMPs and hemoglobin was determined by spectrophotometry. For the experiment, $1 \mathrm{mg} / \mathrm{mL}$ of $\mathrm{HbA}_{1 \mathrm{C}}$ was employed as the binding target. As the concentration of ZnMPs increased $(1,5,20$, and $50 \mathrm{mg} / \mathrm{mL})$, the binding capacity of $\mathrm{ZnMPs}$ with $\mathrm{HbA}_{1 \mathrm{C}}$ increased to $30 \%, 38 \%, 57 \%$, and $76 \%$, respectively. From these results, we concluded that manufactured $\mathrm{ZnMP}$ has the ability to capture $\mathrm{HbA}_{1 \mathrm{C}}$ effectively enough for use in $\mathrm{HbA}_{1 \mathrm{c}}$ purification. The optimum concentration of ZnMP in the reaction mixture was determined after considering the effect of ZnMP on electrochemical signaling (vide infra).

With the prepared ZnMP, we electrochemically analyzed $\mathrm{HbA}_{1 \mathrm{C}}$. The $\mathrm{Hb}_{1 \mathrm{C}}$ portion in total hemoglobin was selectively reacted with FcBA via the cis-diol interaction, and the $\mathrm{HbA}_{1 \mathrm{C}^{-}}$ FcBA conjugate was separated using ZnMPs. ZnMPs can purify all types of hemoglobin, including glycated $\mathrm{HbA}_{1 \mathrm{C}}$ and nonglycated $\mathrm{HbA}_{0}$; however, FcBA interacted only with the glycated portion of $\mathrm{HbA}_{1 \mathrm{c}}$. Thus, the electrochemical signal values were registered according to the concentration of $\mathrm{HbA}_{1 \mathrm{c}}$ based on the bound FcBA molecules. To determine the assay conditions, the $\mathrm{HbA}_{1 \mathrm{C}}$ sample was reacted with $\mathrm{FcBA}$, and the $\mathrm{HbA}_{1 \mathrm{C}^{-}}$ FcBA conjugate was analyzed after being purified with either zinc ion or various concentrations of ZnMPs. Voltammetric measurements were performed with the purified $\mathrm{HbA}_{1 \mathrm{C}}-\mathrm{FcBA}$ conjugate on a gold electrode. From voltammograms, the signal current levels were registered at $400 \mathrm{mV} v s . \mathrm{Ag} / \mathrm{AgCl}$ for the respective analyte concentrations. As the concentration of ZnMPs increased from 1 to $10 \mathrm{mg} / \mathrm{mL}$, the overall electrochemical signal increased (Figure 2). The currents increased in proportion to the concentration of $\operatorname{target} \mathrm{HbA}_{1 \mathrm{C}}$, but showed different signal trends based on the concentrations of ZnMPs $(1,5$, and $10 \mathrm{mg} / \mathrm{mL})$ applied. For the condition of $1 \mathrm{mg} / \mathrm{mL}$ ZnMP in Figure 2A, a sigmoidal plot was registered according to the $\mathrm{HbA}_{1 \mathrm{C}}$ concentration, ranging from 0.0 to $0.6 \mathrm{mg} / \mathrm{mL}$, after which the signal leveled off. Due to the narrow detection 


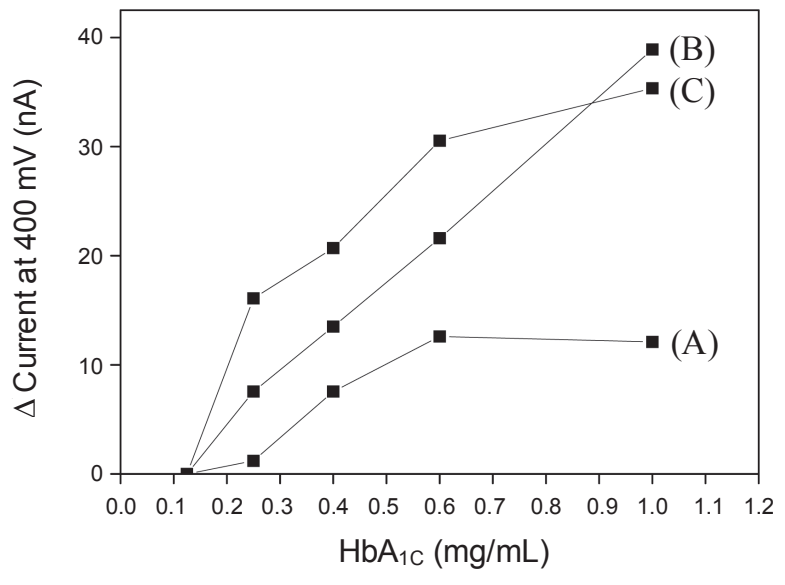

Figure 2. Electrochemical analysis of $\mathrm{HbA}_{1 \mathrm{C}}$ purified from $\mathrm{ZnMPs}$ treatment. Registration of anodic currents at $400 \mathrm{mV} v s . \mathrm{Ag} / \mathrm{AgCl}$ reference electrode from respective voltammograms according to the various concentrations $(0.1 \sim 1.0 \mathrm{mg} / \mathrm{mL})$ of $\mathrm{HbA}_{1 \mathrm{C}}$. The concentrations of ZnMPs are (A) $1 \mathrm{mg} / \mathrm{mL}$, (B) $5 \mathrm{mg} / \mathrm{mL}$, and (C) $10 \mathrm{mg} / \mathrm{mL}$.

range and sigmoidal signal trend, the $1 \mathrm{mg} / \mathrm{mL} \mathrm{ZnMP} \mathrm{condi-}$ tion was not useful. From the test with $10 \mathrm{mg} / \mathrm{mL} \mathrm{ZnMP}$ in Figure $2 \mathrm{C}$, we found that the signal increased fast but leveled off at a low $\mathrm{HbA}_{1 \mathrm{C}}$ concentration, which is not useful for the analysis of $\mathrm{HbA}_{1 \mathrm{C}}$ in the required detection range. The optimum concentration condition for electrochemical detection of $\mathrm{HbA}_{1 \mathrm{C}}$ was considered to be $5 \mathrm{mg} / \mathrm{mL}$ of $\mathrm{ZnMP}$, since it exhibits a linear signal change between 0.0 and $1.0 \mathrm{mg} / \mathrm{mL}$ of $\mathrm{HbA}_{1 \mathrm{C}}$ examined (Figure 2B). Consequently, $5 \mathrm{mg} / \mathrm{mL}$ of $\mathrm{ZnMP}$ was chosen for detecting $\mathrm{HbA}_{1 \mathrm{c}}$ with the developed method. For comparison, $5 \mathrm{mM}$ of zinc chloride was reacted with the $\mathrm{HbA}_{1 \mathrm{c}}-\mathrm{FcBA}$ conjugate. When zinc ion was added, the coagulation process began immediately. The coagulated $\mathrm{HbA}_{1 \mathrm{C}}-\mathrm{FcBA}$ conjugate was collected using a centrifuge, and the electrochemical signal was measured. Electrochemical signals of $\mathrm{HbA}_{1 \mathrm{C}}-\mathrm{FcBA}$ conjugates purified with zinc ion almost corresponded to those in the ZnMP $(1 \mathrm{mg} / \mathrm{mL})$ purification process. In fact, zinc ion and ZnMPs had almost the same effect on the purification of the $\mathrm{HbA}_{1 \mathrm{C}^{-}}$ FcBA conjugate, because hemoglobin purification occurred via the reaction between $\mathrm{HbA}_{1 \mathrm{C}}$ and zinc ion, either in solution or on the surface of the MPs. However, purification using ZnMPs is a faster and more convenient method than centrifugation with zinc ion in solution. Furthermore, ZnMPs capturing $\mathrm{HbA}_{1 \mathrm{C}^{-}}$ FcBA conjugates could be magnetically deposited to the surface of a working electrode, enabling signaling of amplified electrochemical currents.

In the practical analysis, $\mathrm{HbA}_{1 \mathrm{C}}$ is measured as the percentage of glycated hemoglobin $\left(\% \mathrm{HbA}_{1 \mathrm{C}}\right)$ per total hemoglobin $\left(\mathrm{HbA}_{1 \mathrm{C}}+\mathrm{HbA}_{0}\right)$. The reference range for diabetes diagnosis and long-term control is $5 \% \sim 15 \% \mathrm{HbA}_{1 \mathrm{c}}{ }^{9,18}$ To ensure the accuracy of the $\% \mathrm{HbA}_{1 \mathrm{C}}$ sample preparation, $\mathrm{HbA}_{1 \mathrm{C}}$ samples of different concentrations ranging from $0 \%$ to $15 \%$ were prepared by adjusting the total hemoglobin concentration to 1.5 $\mathrm{mg} / \mathrm{mL}$ with $\mathrm{HbA}_{0} . \% \mathrm{HbA}_{1 \mathrm{C}}$ samples were reacted with a fixed concentration of $\mathrm{FcBA}$, and the $\mathrm{HbA}_{1 \mathrm{C}}-\mathrm{FcBA}$ conjugates were purified with ZnMPs. Purified $\mathrm{ZnMP} / \mathrm{HbA}_{1 \mathrm{C}}-\mathrm{FcBA}$ was electrochemically analyzed on a gold electrode with or without a permanent magnet under the working electrode. Calibration curves were drawn using anodic current differences at $400 \mathrm{mV}$ from the respective cyclic voltammograms (Figure 3 ). We found that $\% \mathrm{HbA}_{1 \mathrm{C}}$ values could be detected, registering the increase in current from the ferrocenyl groups bound on $\mathrm{HbA}_{1 \mathrm{c}}$. However, when the $\mathrm{ZnMP} / \mathrm{HbA}_{1 \mathrm{C}}-\mathrm{FcBA}$ was dispersed and measured in the electrolyte, the signal level as well as the detection range of $\% \mathrm{HbA}_{1 \mathrm{C}}$ was not sufficient. The observed detection range was narrow, from $0 \%$ to $6 \% \mathrm{HbA}_{1 \mathrm{C}}$ (Figure $3 \mathrm{~B}$ and $3 \mathrm{C}$ ). To enhance the electrochemical signal by concentrating the conjugate at the electrolyte/electrode interface, we placed a permanent magnet under the working electrode. We could observe amplified signal levels and a wider detection range.

From the calibration with signal amplification (Figure 3A and $3 \mathrm{C}$ ), we found that $\% \mathrm{HbA}_{1 \mathrm{C}}$ values in the range of $0 \%$ $12 \%$ can be detected, covering the reference range for the diagnosis and management of diabetes. It should also be noted that the $\% \mathrm{HbA}_{1 \mathrm{C}}$ values in the range of $6 \% \sim 9 \%$, important for the determination of normal/abnormal blood $\% \mathrm{HbA}_{1 \mathrm{c}}$, were included within the linear region of the calibration curve. ${ }^{18}$

In summary, we have developed an efficient electroanalytical method for $\% \mathrm{HbA}_{1 \mathrm{C}}$ assay. We employed a MP-based concentration of $\mathrm{HbA}_{1 \mathrm{c}}$ to create simple and amplified signaling and demonstrated the utility of a ZnMP-supported concentration method coupled to boronate-diol interactions for $\mathrm{HbA}_{1 \mathrm{C}}$ determination.
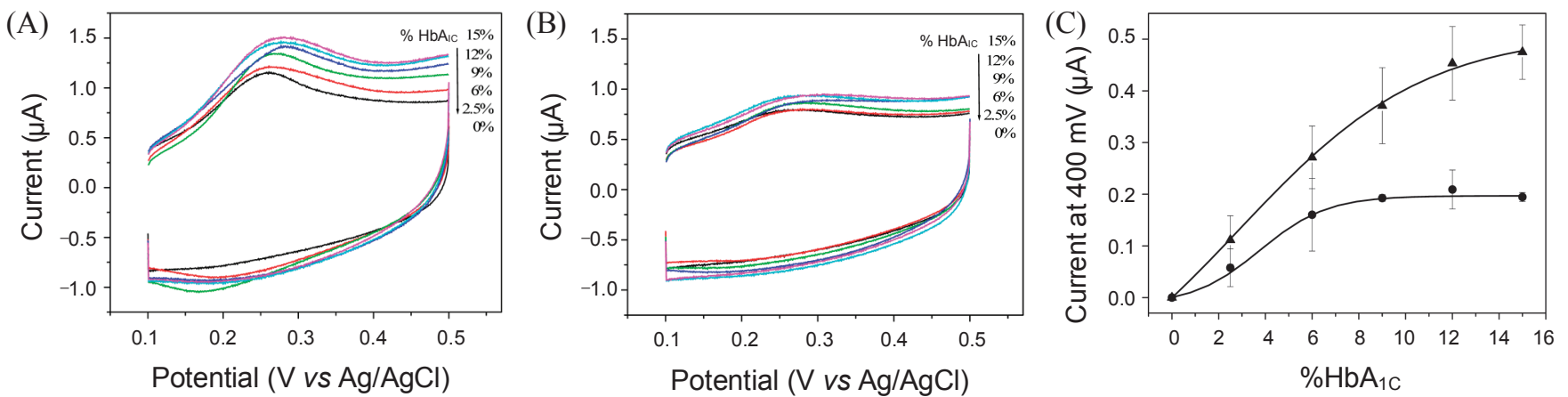

Figure 3. Electrochemical analysis of the $\% \mathrm{HbA}_{1 \mathrm{C}}$. Cyclic voltammograms registered for different $\% \mathrm{HbA}_{1 \mathrm{C}}$ samples with (A) and without (B) a permanent magnet under the working electrode. (C) Calibration curves obtained for $\% \mathrm{HbA}_{1 \mathrm{C}}$ with (triangle) and without (circle) a permanent magnet. Signals were registered from current differences at $400 \mathrm{mV}$ of cyclic voltammograms. The mean of the independent triplicate analysis is shown. 


\section{Experimental Section}

$\mathrm{HbA}_{1 \mathrm{C}}$ was purchased from Fluka and $\mathrm{HbA}_{0}$ was from Fitzerald. FcBA, amine-terminated MP $(\Phi=1 \mu \mathrm{m})$, 1-ethyl-3-(3dimethylaminopropyl) carbodiimide hydrochloride (EDAC), ethylene diamine tetraacetic acid (EDTA), $N$-hydroxysuccinimide (NHS), and $\mathrm{ZnCl}_{2}$ were purchased from Sigma-Aldrich. To purify hemoglobin using MPs, the surface of the MPs was modified with zinc ions. The MP suspension was rinsed with a pyridine buffer $(0.01 \mathrm{M}, \mathrm{pH} 6)$ and resuspended in a phosphate buffer $(0.05 \mathrm{M}, \mathrm{pH} 8)$. EDTA $(0.1 \mathrm{M})$ was activated in the presence of NHS $(0.2 \mathrm{M})$ and $\operatorname{EDAC}(0.1 \mathrm{M})$ in a phosphate buffer at room temperature for $15 \mathrm{~min} .{ }^{15-17}$ Activated EDTA was added to the MPs and stirred gently at room temperature for $8 \mathrm{~h}$. The EDTA-coated MPs were washed with DDW and collected 3 times with a permanent magnet. As a last step, the EDTA-coated MPs were mixed with $10 \mathrm{mM}$ of zinc chloride at room temperature overnight. The final concentration of $\mathrm{ZnMP}$ was $50 \mathrm{mg} / \mathrm{mL}$.

For the determination of binding capacity of ZnMPs to $\mathrm{HbA}_{1 \mathrm{C}}$, various concentrations of ZnMPs were mixed with $1 \mathrm{mg} / \mathrm{mL}$ of $\mathrm{HbA}_{1 \mathrm{C}}$ at a ratio of $1: 1(\mathrm{v} / \mathrm{v})$, and the solutions were set to react for $10 \mathrm{~min}$ at room temperature. Subsequently, the magnetic separation step was conducted, and the absorbance of the supernatants was measured at $415 \mathrm{~nm}$.

For the analysis of $\mathrm{HbA}_{1 \mathrm{C}}$, samples with different percentile concentrations of $\mathrm{HbA}_{1 \mathrm{C}}(0 \% \sim 15 \%)$ were prepared by diluting the $\mathrm{HbA}_{1 \mathrm{C}}$ reagent with $\mathrm{HbA}_{0}$ in $\mathrm{PBS}$. The total concentration of hemoglobin $\left(\mathrm{HbA}_{1 \mathrm{C}}+\mathrm{HbA}_{0}\right)$ in the samples was adjusted to $50 \mu \mathrm{g} / \mathrm{mL}$. FcBA $(0.32 \mathrm{mM})$ was mixed with $\% \mathrm{HbA}_{1 \mathrm{C}}$ samples at a ratio of $1: 1(\mathrm{v} / \mathrm{v})$ for $20 \mathrm{~min}$ at room temperature. After the conjugation reaction was induced, the resulting mixture was purified using ZnMPs. The modified ZnMPs ( $5 \mathrm{mg} / \mathrm{mL}$ ) were combined with the $\mathrm{HbA}_{1 \mathrm{C}}-\mathrm{FcBA}$ conjugate for $10 \mathrm{~min}$. Subsequently, ZnMPs, capturing $\mathrm{HbA}_{1 \mathrm{C}}-\mathrm{FcBA}$ conjugates, were separated using a permanent magnet and washed. For comparison with a method not involving MPs, $5 \mathrm{mM}$ of zinc chloride was also blended with the $\mathrm{HbA}_{1 \mathrm{C}}-\mathrm{FcBA}$ conjugate at a ratio of $1: 1(\mathrm{v} / \mathrm{v})$, according to the procedure developed in our previous work.

For electrochemical signal registration, $\% \mathrm{HbA}_{1 \mathrm{C}}$ samples were reacted under the same conditions for the $\mathrm{HbA}_{1 \mathrm{C}}-\mathrm{FcBA}$ conjugation. Then, the purified product of $\mathrm{ZnMP} / \mathrm{HbA} \mathrm{A}_{1 \mathrm{C}}-\mathrm{FcBA}$ was electrochemically analyzed on a gold electrode. The evaporated gold surfaces were prepared by the resistive evaporation of $200 \mathrm{~nm}$ of Au onto $20 \mathrm{~nm}$ titanium-primed Si[100] wafers. The electrode was treated with a piranha solution containing $\mathrm{H}_{2} \mathrm{SO}_{4} / \mathrm{H}_{2} \mathrm{O}_{2}(4: 1, \mathrm{v} / \mathrm{v})$ for 5 minutes. The area of the working electrode was $0.28 \mathrm{~cm}^{2}$, which was enough to deposit MPs as a sub-monolayer by using magnetic force. A permanent magnet was placed below the gold electrode to enhance the electrochemical signal by concentrating the conjugate at the electrolyte/electrode interface. Electrochemical measurements were carried out with an electrochemical analyzer (model 630B, CH Instruments) connected to a laptop. We used a standard threeelectrode configuration with an evaporated gold working electrode, a platinum auxiliary electrode, and an external $\mathrm{Ag} / \mathrm{AgCl}$ (3 $\mathrm{M} \mathrm{NaCl}, \mathrm{BAS}$ ) reference electrode. Signal current levels were registered at $+400 \mathrm{mV} v s$. $\mathrm{Ag} / \mathrm{AgCl}$ from the backgroundsubtracted cyclic voltammograms under a potential sweep rate of $5 \mathrm{mV} / \mathrm{s}$. The electrochemical signaling cell with the magnet was separated from the potentiostat system to eliminate the influence of magnetism.

Acknowledgments. This work was supported by the National Research Foundation grant (2009-0072107) and the Priority Research Centers Program (2009-0093826) funded by the Ministry of Education, Science and Technology, Korea.

\section{References}

1. (a) Shinkal, M. J. Biosci. Bioeng. 2002, 94, 606. (b) Jang, J. H.; Lim, H. B. Microchem. J. 2010, 94, 148.

2. Olsvik, O.; Popovic, T.; Skjerve, E.; Cudjoe, K. S.; Hornes, E.; Ugelstad, J.; Uhlen, M. Clin. Microbiol. Rev. 1994, 7, 43.

3. (a) Schultz, N.; Hobley, T. J.; Syldatk, C. Biotechnol. Lett. 2007, 29, 365. (b) Hsieh, H. C.; Kuan, I. C.; Lee, S. L.; Tien, G. Y.; Wang, Y. J.; Yu, C. Y. Biotechnol. Lett. 2009, 31, 557.

4. (a) Miura, T.; Satoh, T.; Takeuchi, H. Biochim. Biophys. Acta 1998, 1384, 171. (b) Doerr, A. J.; McLendon, G. L. Inorg. Chem. 2004, 43,7916

5. Gaberc-Porekar, V.; Menart, V. J. Biochem. Biophys. Methods 2001, 49, 335.

6. (a) Rifkind, J. M.; Heim, J. M.; Clague, J. E. Biochemistry 1977, 16, 4438. (b) Oelshlegel, F. J.; Brewer, G. J.; Knutsen, C.; Prasad, A. S.; Schoomaker, B. Arch. Biochem. Biophys. 1974, 163, 742. (c) Gilman, J. G.; Brewer, G. J. Biochem. J. 1978, 169, 625. (d) Carrell, R. W.; Lehmann, H. J. Clin. Phathol. 1981, 34, 796.

7. (a) Lippincott, J.; Fattor, T. J.; Lemon, D. D.; Apostol, I. Anal. Biochem. 2000, 284, 247. (b) Khromova, V. S.; Myshkin, A. E. Russ. J. Gen. Chem. 2002, 72, 1645.

8. (a) Frantzen, F.; Grimsrud, K.; Heggli, D. E.; Faaren, A. L.; Løvli, T.; Sundrehagen, E. Clin. Chem. 1997, 43, 2390. (b) Frantzen, F.; Grimsrud, K.; Heggli, D. E.; Sundrehagen, E. Hemoglobin 1997, 21,155 .

9. Pendleton, N.; Clague, J. E.; Cobain, M.; Thethi, K.; Jones, M.; Horan, M. A.; McInnes, L.; Rabbitt, P. M. A. Arch. Gerontol. Geriatr. 2005, 41, 289.

10. Cussimanio, B.; Booth, A.; Todd, P.; Hudson, B.; Khalifah, R. Biophys. Chem. 2003, 105, 743.

11. (a) Li, Y. C.; Jeppsson, J.-O.; J-Karlsson, M.; Larsson, E. L.; Jungvid, H.; Galaev, I. Y.; Mattiasson, B J. Chromatogr. B 2002, 776, 149. (b) Stöllner, D.; Stöcklein, W.; Scheller, F.; Warsinke, A. Anal. Chim. Acta 2002, 470, 111. (c) De la Calle Guntinas, M. B.; Wissiack, R.; Bordin, G.; Rodriguez, A. R. J. Chromatogr. B 2003, 791, 73. (d) Kim, E. J.; Song, S. Y.; Lee, B. Y.; Yoon, H. C. BioChip J. 2010, 4, 16. (e) Busto, M.; Montes-Bayon, M.; Anon, E.; Sanz-Medel, A. J. Anal. At. Spectrom. 2008, 23, 758.

12. (a) Pribyl, J.; Skladal, P. Biosens. Bioelectron. 2006, 21, 1952. (b) Tanaka, T.; Matsunaga, T. Biosens. Bioelectron. 2001, 16, 1089. (c) Tanaka, T.; Tsukube, S.; Izawa, K.; Okochi, M.; Lim, T. K.; Watanabe, S.; Harada, M.; Matsunaga, T. Biosens. Bioelectron. 2007, 22, 2051.

13. (a) Barba, V.; Farfan, N.; Losi, S.; Zanello, P. Inorg. Chim. Acta 2006, 359, 1269. (b) Liu, S.; Wollenberger, U.; Katterle, M.; Scheller, F. W. Sens. Act. B-Chem. 2006, 113, 623.

14. Son, S. Y.; Yoon, H. C. BioChip J. 2009, 3, 164.

15. Bernkop-Schnürch, A.; Krajicek, M. E. J. Control. Release 1998, $50,215$.

16. Görlich, D.; Frey, S. PCT Patent 2009, WP2009/019012.

17. Milne, K.; Lawlor, M. U. S. Patent 2009, 7592182.

18. Little, R. R.; England, J. D.; Wiedmeyer, H. M.; McKenzle, E. M.; Mitra, R.; Erhart, P. M.; Durham, J. B.; Goldstein, D. E. Clin. Chem. 1986, 32, 358. 